\title{
Contribuição ao conhecimento de espécies venezuelanas de Lespesia Robineau-Desvoidy (Diptera, Tachinidae, Exoristinae), com descrições de novas espécies
}

\author{
Ronaldo Toma ${ }^{1}$
}

\begin{abstract}
${ }^{1}$ Universidad de Carabobo, Facultad de Ciencias y Tecnología, Departamento de Biología, Bárbula, antiguo Decanato de Ciencias de la Salud, Valencia, Carabobo, C. P. 2005, rtkuna1@gmail.com
\end{abstract}

\begin{abstract}
Contribution to the knowledge of Venezuelan species of Lespesia Robineau-Desvoidy (Diptera, Tachinidae), with descriptions of new species. A taxonomic study on Venezuelan species of the genus Lespesia Robineau-Desvoidy, 1863 (Diptera, Tachinidae) is done, based on the collection of the "Museo del Instituto de Zoología Agrícola Francisco Fernández Yépez (MIZA) de la Universidad Central de Venezuela - Maracay”. Six species are recognized, two of which are described as new, Lespesia giovannae sp. nov. and Lespesia oscari sp. nov., and three recorded from Venezuela for the first time: Lespesia affinis (Townsend, 1927), Lespesia protoginoi (Blanchard, 1966) and Lespesia spitzi Guimarães, 1983. Redescriptions and key to species are given.
\end{abstract}

KEYWORDS. Diptera; Lespesia; Neotropical Region; Tachinidae; Taxonomy.

RESUMO. Contribuição ao conhecimento de espécies venezuelanas do gênero Lespesia Robineau-Desvoidy (Diptera, Tachinidae), com descrições de novas espécies. Foi realizado um estudo taxonômico de espécies venezuelanas do gênero Lespesia RobineauDesvoidy, 1863 (Diptera, Tachinidae), baseado na coleção do "Museo del Instituto de Zoología Agrícola Francisco Fernández Yépez (MIZA) de la Universidad Central de Venezuela - Maracay”. Seis espécies foram reconhecidas, dentre estas duas são descritas como novas, Lespesia giovannae sp. nov. e Lespesia oscari sp. nov., e três são registradas pela primeira vez para a Venezuela: Lespesia affinis (Townsend, 1927), Lespesia protoginoi (Blanchard, 1966) e Lespesia spitzi Guimarães, 1983. São apresentadas redescrições e chaves para as espécies.

PALAVRAS-CHAVE. Diptera; Lespesia; Região Neotropical; Tachinidae; Taxonomia.

O gênero Lespesia foi descrito por Robineau-Desvoidy (1863) com base em um espécime macho identificado como Erycia ciliata Macquart, 1834. Segundo Sabrosky (1980), Robineau-Desvoidy baseou sua descrição sobre um exemplar, proveniente dos Estados Unidos, erroneamente identificado como a espécie de Macquart. No mesmo trabalho, o autor citou uma aplicação que ele próprio havia submetido anteriormente (Sabrosky, 1979) à Comissao Internacional de Nomeclatura Zoológica para designação da espécie-tipo de Lespesia e afirmou que o espécime original de RobineauDesvoidy era idêntico a L. anisotae (Webber, 1930), designado posteriormente como espécie-tipo desse gênero em plenária da Comissão Internacional de Nomenclatura Zoológica (ICZN, 1983).

A distribuição das espécies de Lespesia é restrita ao Novo Mundo, sendo um dos maiores e mais importantes gêneros de moscas parasitóides no hemisfério ocidental (Sabrosky, 1980). Os últimos catálogos para as Regiões Neártica (O`Hara \& Wood, 2004) e Neotropical (Guimarães, 1971) posicionam o gênero dentro da tribo Eryciini. As espécies de Lespesia depositam ovos membranosos sobre o corpo de seus hospedeiros, larvas de Lepidoptera (Allen, 1926).

Revisões para as espécies neárticas foram realizadas por Webber (1930) (= Achaetoneura Brauer \& Bergestamm), Beneway (1963) e Sabrosky (1980). Para a Região Neotropical existem poucos trabalhos de revisão: Thompson (1966) com a revisão das espécies de Trinidad dos gêneros
Lespesia e Prophryno (= Lespesia), e Guimarães (1983) com a revisão das espécies brasileiras de Lespesia. Atualmente o gênero conta com 64 espécies descritas para o Novo Mundo, sendo 35 para a Região Neotropical (Guimarães 1971, 1983; O`Hara \& Wood, 2004). Para a Venezuela duas espécies foram registradas até o presente trabalho: $L$. archippivora (Riley, 1871), por Notz (1972), e L. erythrocauda (Curran, 1934), originalmente descrita para Guanoco, Venezuela. Esta última, no entanto, possivelmente não pertença à Lespesia, pois apresenta características incompatíveis com o gênero.

O presente estudo tem como intuito auxiliar no reconhecimento de espécies venezuelanas de Lespesia através de redescrições e/ou descrições e chaves de identificação, contribuindo dessa forma para a ampliação do conhecimento taxonômico deste gênero para a Região Neotropical.

\section{MATERIAL E MÉTODOS}

O trabalho se baseou no material depositado na coleção entomológica do "Museo del Instituto de Zoología Agrícola Francisco Fernández Yépez (MIZA) de la Universidad Central de Venezuela - Maracay”. A terminologia utilizada seguiu predominantemente a de McAlpine (1981); alguns términos foram retirados de Guimarães (1983). Abreviaturas utilizadas: reg. nov. $=$ novo registro.

Os exemplares machos foram colocados em uma câmara úmida durante 24 horas. Em seguida, dissecou-se a terminália, 
que foi fervida em Hidróxido de Potássio à 10\%, durante 15 minutos, e desidratada em uma série alcoólica. Logo após, o material foi colocado em glicerina, onde foi examinado e ilustrado com auxílio de um microscópio estereoscópico Leica MZ75, com câmara clara. Após o exame do material, as partes dissecadas foram guardadas em pequenos tubos plásticos contendo glicerina e foram montadas junto com o exemplar seco.

\section{RESULTADOS}

\section{Lespesia Robineau-Desvoidy}

Lespesia Robineau-Desvoidy, 1863:567. Espécie-tipo: Achaetoneura anisotae Webber, 1930 (veja O`Hara \& Wood 2004); Beneway, 1963 (revisão das espécies da América do Norte); Sabrosky \& Arnaud Jr., 1965 (catálogo das espécies neárticas); Thompson, 1965 (revisão das espécies de Trinidad); Guimarães, 1971 (catálogo das espécies neotropicais); Sabrosky, 1980 (chaves para as espécies neárticas); Guimarães, 1983 (revisão das espécies brasileiras).

Achaetoneura Brauer \& Bergestamm,1891:334. Espécie-tipo: Achaetoneura hesperus Brauer \& Bergestamm, 1893 (= Masicera frenchii Williston, 1889), por designação subseqüente de Townsend, 1908; Allen, 1926 (nota); Webber, 1830 (revisão das espécies norte-americanas); Townsend, 1941 (redescrição); Beneway, 1963 (como sinônimo de Lespesia).

Parafrontina Brauer \& Bergestamm, 1893:115. Espécie-tipo: Parafrontina apicalis Brauer \& Bergestamm, 1893 (= Tachina archippivora Riley, 1871), por monotipia; Townsend, 1941 (redescrição); Beneway, 1963 (como sinônimo de Lespesia).

Rileyella Townsend, 1909:249. Especie-tipo: Tachina aletiae Riley, 1879, por designação original; Townsend, 1941 (redescrição); Beneway, 1963 (como sinônimo de Lespesia).

Zygofrontina Townsend, 1915:427. Espécie-tipo: Zygofrontina capitis Townsend, 1915, por designação original; Townsend, 1941 (redescrição); Beneway, 1963 (como sinônimo de Lespesia).

Masiceropsis Townsend, 1916a:178. Espécie-tipo: Masicera pauciseta Coquillett, 1897 (= Tachina archippivora Riley, 1871), por designação original; Townsend, 1941 (redescrição); Beneway, 1963 (como sinônimo de Lespesia).

Ypophaemyia Townsend, 1916b:75. Espécie-tipo: Ypophaemyia malacosomae Townsend, 1916 (= Tachina archippivora Riley, 1871), por designação original; Townsend, 1941 (redescrição); Beneway, 1963 (como sinônimo de Lespesia).

Gymnoerycia Townsend, 1916b:75. Espécie-tipo: Gymnoerycia rubra Townsend, 1916, por designação original; Townsend, 1941 (redescrição); Sabrosky, 1980 (como sinônimo de Lespesia).

Euparafrontina Brèthes, 1917:17. Espécie-tipo: Euparafrontina martinezi Brèthes, 1917, por monotipia; Tonwsend, 1941 (redescrição); Beneway, 1963 (como sinônimo de Lespesia).

Prophryno Townsend, 1927:262. Espécie-tipo: Prophryno aurulans Townsend, 1927, por designação original; Townsend, 1941 (redescrição); Thompson, 1965 (revisão das espécies de Trinidad); Guimarães, 1971 (como sinônimo de Lespesia).

Achaetoneuropsis Townsend, 1927:272. Espécie-tipo: Achaetoneuropsis affinis Townsend, 1927, por designação original; Townsend, 1941 (redescrição); Beneway, 1963 (como sinônimo de Lespesia).

Myiosturmia Townsend, 1927:272. Espécie-tipo: Myiosturmia mixta Townsend, 1927, por designação original; Townsend, 1941 (redescrição); Guimarães, 1983 (como sinônimo de Lespesia).

Zygofrontiniopsis Blanchard, 1959:173. Espécie-tipo: Zygofrontiniopsis williamsi Blanchard, 1959, por designação original; Guimarães, 1983 (como sinônimo de Lespesia).

Frontina, autores non Meigen

Diagnose. Olhos glabros, levemente ou densamente pilosos. Cerdas ocelares reduzidas ou fortes. Antenas alcançando o quarto inferior da face; flagelômeros largos e arredondados no ápice; pedicelos geralmente menos de um terço do comprimento dos flagelômeros. Aristas nuas, com terceiro segmento alargado na base e atenuado em direção ao ápice. Faciálias com cerdas supravibrissais eretas e variando de fracas a fortes. Cerdas subvibrissais geralmente formando uma fileira com menos de quatro cerdas, com extensão não maior que a metade do comprimento da fileira de cerdas supravibrissais. Machos e fêmeas geralmente com dois pares de cerdas fronto-orbitais reclinadas alinhadas às cerdas frontais superiores, e fêmea com cerdas fronto-orbitais proclinadas. Parafaciálias nuas. Vibrissas posicionadas no nível da margem oral. Genas pilosas. Palpos bem desenvolvidos e clavados. Tórax com polinosidade cinza a amarelo; mesonoto com quatro faixas escuras. Cerdas acrosticais 3:3, dorsocentrais 3:4; intra-alares 3:3; pré-alares 1 ; catepisternais geralmente 4. Escutelo: 3 ou 4 cerdas laterais, um par de cerdas discais e um par de cerdas apicais cruzadas e eretas. Proepisterno nu. Pernas escuras; tíbias posteriores com uma fileira de cerdas ântero-dorsais, cada cerda separada uma da outra por não mais que três vezes a sua largura. Asas com veia $\mathrm{M}$ terminando na margem da asa separada da veia $R_{4+5}$; veias nuas, exceto a base da veia $R_{4+5}$ com 2 ou 3 cerdas, última seção da veia $\mathrm{A}_{1}$ menor que metade do comprimento da seção anterior. Abdome sem cerdas discais sobre os tergitos 3 e 4; sintergito $1+2$ e tergito 3 com ou sem cerdas marginais medianas, se presente, somente um par por segmento; tergito 4 com uma fileira de marginais medianas e tergito 5 com cerdas dispostas irregularmente.

Chave para identificação de espécies venezuelanas.

A confecção das chaves foi baseada no material estudado e complementada com informações de Guimarães (1983).

\section{Chave para machos}

1. Olhos densamente pilosos L. oscari sp. nov. Olhos nus ou levemente pubescentes ............................... 2

2. Garras tarsais mais curtas que o último segmento tarsal..3 Garras tarsais mais longas que o último segmento tarsal.4

3. Escutelo com quatro cerdas laterais; largura do vértice cerca de 0,33 da largura da cabeça

L. protoginoi (Blanchard)

Escutelo com três cerdas laterais; largura do vértice cerca de 0,40 da largura da cabeça

L. archippivora (Riley)

4. Cerdas ocelares curtas, com cerca de um terço do tamanho da distância da fronte entre as cerdas ocelares e a base da antena L. spitzi Guimarães

Cerdas ocelares com cerca da metade do tamanho da distância da fronte entre as cerdas ocelares e a base da antena L. affinis (Townsend)

Chave para fêmeas

1. Largura do vértice cerca de 0,40 da largura da cabeça .. 2 Largura do vértice não ultrapassando 0,35 da largura da cabeça 
2. Sintergito $1+2$ sem cerdas marginais medianas; tíbia média com três cerdas ântero-dorsais fortes

L. giovannae sp. nov.

Sintergito $1+2$ com cerdas marginais medianas; tíbia média com uma cerda ântero-dorsal forte e uma ou duas cerdas ântero-dorsais com cerca de um terço do seu tamanho

L. archippivora (Riley)

3. Olhos densamente pilosos L. oscari sp. nov.

Olhos nus ou levemente pubescentes 4

4. Cerdas ocelares curtas, cerca de um terço do tamanho da distância entre as cerdas ocelares e a base da antena .... L. spitzi Guimarães

Cerdas ocelares mais longas, cerca da metade ou mais da metade do tamanho da distância entre as cerdas ocelares e a base da antena 5

5. Tergitos 3 a 5 com polinosidade cinza ocupando de forma irregular os três quartos basais; sintergito $1+2$ sem e tergito 3 com um par de cerdas marginais medianas ....... . L. protoginoi (Blanchard)

Tergitos 3 a 5 com polinosidade cinza ocupando de forma irregular os dois terços basais; sintergito $1+2$ e tergito 3 sem cerdas marginais medianas .

L. affinis (Townsend)

\section{Lespesia affinis (Townsend, 1927)}

(Figs. 1, 5)

Achaetoneuropsis affinis Townsend, 1927: 282 (Localidade-tipo: Cantareira, São Paulo, Brasil).

Lespesia affinis; Beneway, 1963 (combinação de nomes para Lespesia); Guimarães, 1971 (catálogo neotropical), 1983 (revisão das espécies brasileiras).

Myiosturmia mixta Townsend, 1927: 331 (Localidade-tipo: São Paulo, Itaquaquecetuba, Brasil); Guimarães, 1983 (como sinônimo de Lespesia affinis).

Diagnose. Parafrontálias e parafaciálias com polinosidade cinza a amarelo pálido. Cerdas ocelares cerca da metade do tamanho da distância entre as inserções das cerdas ocelares e a base da antena. Abdome negro com polinosidade cinza, a dos tergitos 3 a 5 ocupando de forma irregular os dois terços basais. Sintergito $1+2$ e tergito 3 sem cerdas marginais medianas.

Redescrição. Macho. Comprimento: 8,0 - 10,0 mm. Olhos levemente pubescentes. Largura do vértice aproximadamente 0,30 da largura da cabeça. Parafrontálias e parafaciálias com polinosidade cinza a amarelo pálido. Antenas negras com a extremidade distal dos pedicelos castanho-avermelhada. Cerdas ocelares cerca da metade do tamanho da distância entre as inserções das cerdas ocelares e a base das antenas. Cerdas verticais internas fortes e cerdas verticais externas reduzidas. Parafrontálias pilosas externamente às cerdas frontais. Faciálias com uma fileira de cerdas de aproximadamente um quarto do comprimento das vibrissas e estendendo-se dois terços da distância das vibrissas à base das antenas. Escutelo com quatro pares de cerdas laterais, um par de cerdas discais e um par de cerdas apicais cruzadas, com cerca de um terço do tamanho das cerdas escutelares subapicais. Garras tarsais anteriores normais. Tíbias médias com somente uma cerda ântero-dorsal forte próximo do meio. Tíbias posteriores com uma cerda um pouco mais longa que as da fileira de cerdas ântero-dorsais, situada próximo ao meio. Abdome negro com polinosidade cinza, a dos tergitos 3 a 5 ocupando de forma irregular os dois terços basais. Sintergito 1+2 e tergito 3 sem cerdas marginais medianas. Genitália (Figs. 1 e 5): cercos e surstilos finalizando aproximadamente na mesma altura; cercos relativamente delgados e curvados na base; surstilos robustos e em forma de um dedo polegar.

Fêmea. Semelhante ao macho, excepto por: cerdas verticais externas aproximadamente um terço do tamanho das cerdas verticais internas, dois pares de cerdas fronto-orbitais proclinadas e garras tarsais anteriores curtas.

Material examinado. VENEZUELA. Amazonas: Santa Lucía, Río Negro, 1 macho, 24.XI.1984, E. Osuna \& A. Chacon; San Carlos, Río Negro, 1 macho, 24.VI.1984, L. J. Joly \& J. Demarmels cols. Aragua: Villa de Gura, Estación Experimental Cataurito, 1 macho, 21.X.1982, J, Demarmels col. (em Perente charops); Maracay: Pozo Diablo (500m), 1 macho e 2 fêmeas, 8.IX.1951, H. Arnal col. Miranda: San Diego, 19.I.1962, sem coletor.

Distribuição geográfica. VENEZUELA(Miranda, Aragua, Amazonas) Lespesia affinis (Townsend, 1927), Lespesia protoginoi (Blanchard, 1966) and Lespesia spitzi Guimarães, 1983.reg. nov., BRASIL (Bahia, Distrito Federal, Mato Grosso do Sul, Minas Gerais, Paraná, Rio de Janeiro, São Paulo, Santa Catarina).

Comentários. Segundo Guimarães (1983), L. affinis é a espécie mais comum na América do Sul e tem sido criada em várias espécies de lagartas que constituem pragas florestal e agrícola. O exemplar do Estado de Aragua traz um novo registro de hospedeiro para esta espécie, Perente charops (Boisduval) (Lepidoptera, Pieridae). As cerdas verticais externas das fêmeas examinadas são relativamente mais longas que as dos exemplares redescritos por Guimarães (1983) e são assumidas aqui como uma variação intraespecífica.

\section{Lespesia archippivora (Riley, 1871)}

(Figs. 2, 6)

Tachina archippivora Riley, 1871: 150. (Localidade-tipo: Missouri, Estados Unidos).

Masicera archippivora; Williston, 1889 (hospedeiro).

Achaetoneura archippivora; Allen, 1926 (notas sobre espécies americanas); Webber, 1930 (revisão de espécies norte-americanas).

Lespesia archippivora; Beneway, 1963 (combinação de nome para Lespesia); Sabrosky \& Arnaud, 1965 (catálogo neártico); Sabrosky, 1980 (chaves para espécies neárticas), Guimarães, 1971 (catálogo neotropical), 1983 (revisão das espécies brasileiras); O`Hara \& Wood, 2004 (catálogo neártico)

Zygofrontina capitis Townsend, 1915: 427 (Localidade-tipo: Casma, Peru); Guimarães, 1983 (como sinônimo de Lespesia archippivora)

Lespesia capitis; Beneway, 1963 (combinaçao de nome para Lespesia); Thompson, 1966 (revisão das espécies de Trinidad); Guimarães, 1971 (catálogo neotropical).

Ypophaemyia malacossomae brasiliensis Townsend, 1917: 231 (Localidadetipo: Mato Grosso do Sul, Corumbá, Brasil); Guimarães, 1983 (como sinônimo de Lespesia archippivora). 

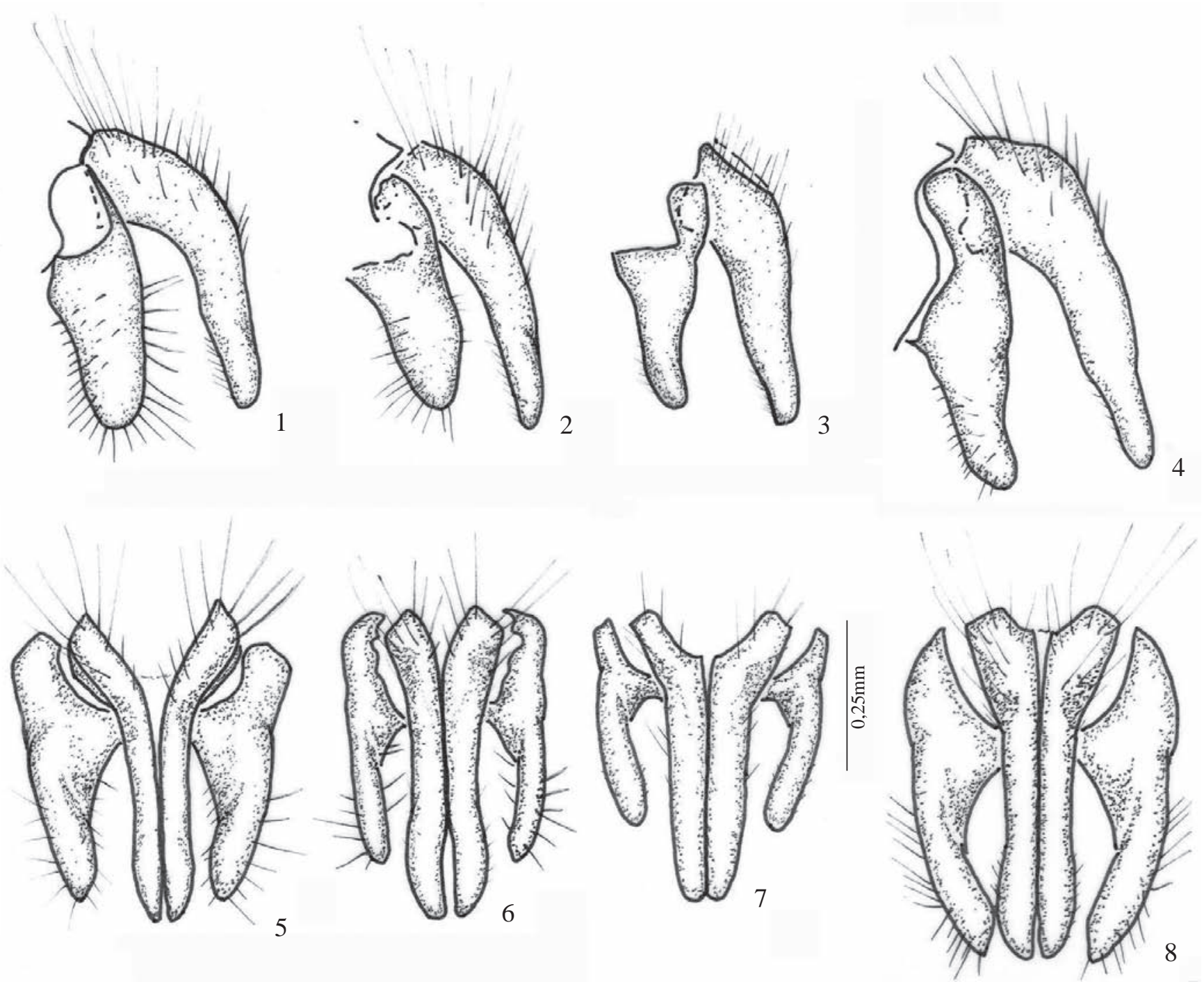

Figs. 1-8. 1-4. Cercos e surstilos, vista lateral: 1, Lespesia affinis (Townsend); 2, L. archippivora (Riley); 3, L. oscari sp. nov.; 4, L. spitzi Guimarães. 5-8. Cercos e surstilos, vista posterior: 5, Lespesia affinis; 6, L. archippivora; 7, L. oscari sp. nov.; 8, L. spitzi.

Lespesia brasiliensis; Guimarães, 1971 (combinação de nome para Lespesia).

Diagnose. Largura do vértice cerca de 0,40 da largura da cabeça. Garras tarsais mais curtas que o último segmento tarsal. Escutelo com três cerdas laterais. Abdome negro, tergito 3 a 5 com polinosidade cinza irregular ocupando os três quartos basais. Sintergito $1+2$ e tergito 3 com um par de cerdas marginais medianas, o par do sintergito $1+2$ fraco.

Redescrição. Macho. Comprimento: 5,0 - 8,0 mm. Olhos levemente pubescentes. Largura do vértice cerca de 0,40 da largura da cabeça. Parafrontálias e parafaciálias com pilosidade cinza, as parafrontálias levemente amareladas. Antenas negras, flagelômeros cerca de quatro vezes o tamanho dos pedicelos. Cerdas ocelares pouco mais da metade do tamanho da distância entre as inserções das cerdas ocelares e a base das antenas. Cerdas verticais externas cerca da metade do comprimento das cerdas verticais internas. Parafrontálias pilosas externamente às cerdas frontais, com presença de poucas cerdas. Faciálias com uma fileira de cerdas variando entre um terço a um quarto do tamanho das vibrissas e estendendo-se dois terços da distancia das vibrissas à base das antenas. Escutelo com três cerdas laterais, um par de cerdas discais, e um par de cerdas apicais obliquas e cerca de um terço do tamanho das cerdas escutelares subapicais. Tíbias médias com uma cerda ântero-dorsal forte e uma ou duas cerdas com cerca de um terço do seu tamanho e posicionadas acima dela. Tíbias posteriores com uma cerda mediana cerca de duas vezes mais longa que as da fileira de cerdas ânterodorsais. Garras tarsais mais curtas que o último segmento tarsal. Abdome negro, tergito 3 a 5 com polinosidade cinza irregular ocupando os três quartos basais. Sintergito $1+2$ e tergito 3 com um par de cerdas marginais medianas, o par do sintergito 1+2 fraco. Genitália (Figs. 2 e 6): cercos terminando além do ápice dos surstilos; cercos, em vista lateral, delgados e curvados próximo à base; surstilos mais curtos que os cercos, robustos na base e afilado no ápice em vista lateral.

Fêmea. Semelhante al macho, excepto por: antenas com flagelômeros castanho-alaranjados e dois pares de cerdas orbitais proclinadas. 
Material examinado. VENEZUELA. Miranda: Autopista ValenciaCaracas (km 50) (440m), 6 machos e 4 fêmeas, 15.X.1999, O. Hernández col. (em Danaus plexippus). Portuguesa: San Nicolas (180m), fêmea, 18.VI.1976, F. Ribot col. (Em Spodoptera frugiperda, Lepidoptera).

Distribuição. CANADÁ (British Columbia, Alberta, Ontario), ESTADOS UNIDOS (Washington, Wisconsin, Michigan, New York, Maine, New Hampshire, Massachusett, Oregon, Idaho, South Dakota, Iowa, Illinois, Indiana, Ohio, Nebraska, Pennsylvania, New Jersey, California, Kansas, Missouri, Tennessee, Virginia, Arizonas, New Mexico, Texas, Arkansas, Lusiana, Mississippi, South Carolina, Florida), MÉXICO (Sonora, Distrito Federal), VENEZUELA (Miranda, Maracay, Portuguesa), PERU (Ancash), BRASIL (Distrito Federal, Mato Grosso do Sul).

Comentários. Segundo Guimarães (1983), Lespesia archippivora se diferencia das demais espécies pelas garras tarsais curtas nos machos e pelo vértice largo em ambos os sexos. Um novo registro de hospedeiro é assinalado para esta espécie, Danaus plexippus (Linnaeus), Lepidoptera, Nymphalidae.

\section{Lespesia giovannae sp. nov.}

$$
\text { (Fig. } 9 \text { ) }
$$

Diagnose. Largura do vértice cerca de 0,40 da largura da cabeça. Tíbias médias com três cerdas ântero-dorsais fortes Sintergito $1+2$ sem cerdas marginais medianas. Abdome com sintergito $1+2$ a tergito 4 castanho com polinosidade cinza. Tergito 5 castanho-alaranjado com polinosidade amarela forte. Sintergito $1+2$ sem cerdas marginais medianas e tergito 3 com um par de cerdas marginais medianas.

Descrição. Fêmea. Comprimento: 12,0 mm. Olhos glabros. Largura do vértice cerca de 0,40 da largura da cabeça. Parafrontálias e parafaciálias com polinosidade cinza levemente amarelo. Flagelômeros negros, pedicelos e escapos alaranjados; flagelômeros duas vezes o tamanho dos pedicelos. Cerdas ocelares pouco mais de um terço da distância entre as inserções das cerdas ocelares e a base das antenas. Cerdas verticais externas pouco mais da metade do tamanho das cerdas verticais internas. Parafrontálias com pêlos externamente à fileira de cerdas frontais, com algumas cerdas fortes com cerca da metade do tamanho das cerdas frontais. Faciálias com uma fileira de cerdas de aproximadamente um terço do tamanho da vibrissa e estendendo-se dois terços da distância das vibrissas à base das antenas. Escutelo com três pares de cerdas laterais, um par de cerdas discais, e um par de cerdas apicais oblíquas e cruzadas [estão quebradas, mas é provável que não alcance um terço do tamanho das cerdas escutelares subapicais]. Tíbias médias com três cerdas ântero-dorsais fortes, posicionadas do meio para base e com tamanho decrescente nesse sentido, a mais proximal cerca da metade do tamanho da segunda cerda, e esta cerca de dois terços do tamanho da cerda mais distal; estas pouco mais da metade do tamanho da tíbia. Tíbias posteriores com uma cerda de pouco menos do dobro do tamanho das da fileira de cerdas ântero-dorsais, situada próximo ao meio. Abdome com sintergito $1+2$ a tergito 4 castanho com polinosidade cinza. Tergito 5 castanho-alaranjado com polinosidade amarela forte. Sintergito $1+2$ sem cerdas marginais medianas e tergito 3 com um par de cerdas marginais medianas.

Macho. Não conhecido.

Material-tipo: Holótipo fêmea. VENEZUELA. Portuguesa: Estación Experimental San Nicolas, Guanare (180m), 13.X.1965, E. Martin col (MIZA).

Distribuição geográfica. VENEZUELA (Portuguesa)

Etimologia. O nome foi dado em homenagem a Giovanna Sartoris, bióloga do Centro de Controle de Zoonoses de São Paulo.

Comentários. A espécie coincide com L. danai (Townsend, 1940) e L. archippivora na chave para fêmeas de Guimarães (1983), mas se diferencia de ambas pela ausência de cerdas marginais medianas no sintergito 1+2 e pela tíbia média com três cerdas fortes.

\section{Lespesia oscari sp. nov.}

(Figs. 3, 7, 10)

Diagnose. Olhos densamente pilosos. Parafrontálias e parafaciálias com polinosidade amarelo-dourado. Cerdas verticais externas finas e cerca de pouco menos da metade das cerdas verticais internas. Abdome negro; tergito 3 e 4 com polinosidade cinza ocupando de forma irregular os três quarto basais; tergito 5 com polinosidade amarela. Sintergito $1+2$ e tergito 3 com um par de cerdas marginais medianas, o primeiro fraco.

Descrição. Macho. Comprimento: 6,0 - 7,0 mm. Olhos densamente pilosos. Largura do vértice cerca de 0,30 da largura da cabeça. Parafrontálias e parafaciálias com polinosidade amarelo-dourado. Antenas negras; flagelômeros cerca de quatro vezes o tamanho dos pedicelos. Cerdas ocelares ultrapassando a metade do tamanho da distância entre as inserções das cerdas ocelares e a base das antenas. Cerdas verticais externas finas e cerca de pouco menos da metade das cerdas verticais internas. Faciálias com cerdas com cerca de um terço do tamanho da vibrissa e estendendo-se três quartos da distancia das vibrissas à base das antenas. Escutelo com quatro pares de cerdas laterais, um par de cerdas discais e um par de cerdas apicais longas cerca de pouco menos de dois terços do tamanho das cerdas subapicais. Tíbias médias com uma forte cerda ântero-dorsal no centro. Tíbias posteriores com uma cerda mediana pouco menor que o dobro do tamanho das da fileira de cerdas ântero-dorsais. Abdome negro; tergito 3 e 4 com polinosidade cinza ocupando de forma irregular os três quarto basais; tergito 5 com polinosidade amarela. Sintergito $1+2$ e tergito 3 com um par de cerdas marginais medianas, o primeiro fraco. Genitália (Figs. 3 e 7): surstilos terminando antes do ápice dos cercos e cerca de pouco menos de dois terços do tamanho destes. Cercos, em vista lateral, afilandose em direção ao ápice; em vista posterior, cercos não tão alargados e surstilos curvados ligeiramente para dentro.

Fêmea. Semelhante ao macho, mas difere por: vértice ligeiramente mais largo, cerdas verticais externas mais grossas, dois pares de cerdas orbitais proclinadas e relação de proporção menor entre flagelômeros e pedicelos. 


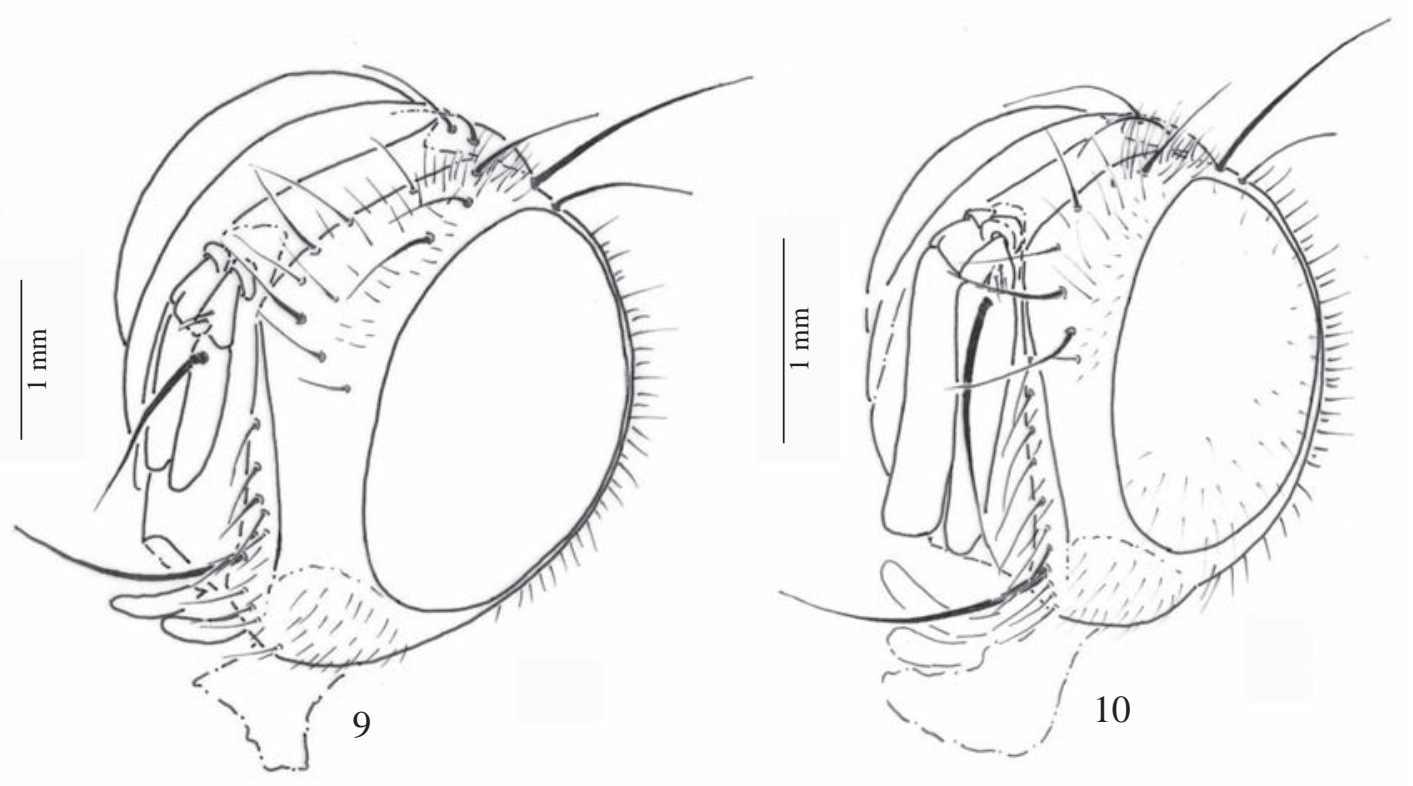

Figs. 9-10. Cabeça, vista laterofrontal 9, Lespesia giovannae sp. nov.; 10, L. oscari sp. nov.

Material-tipo: Holótipo macho. VENEZUELA. Barinas: La Chimenea (1500m), 1-6.VI.1973, J. Salcedo col (MIZA). Parátipo: 1 fêmea, Miranda: S O. Panaguire, Valle Río Cuira (230m) (10²12’ N; 66º 17’ O.), 18-21.IX.1979, F. Y. Fernández \& J. A Clavijo cols (MIZA).

Distribuição geográfica. VENEZUELA: (Miranda, Barinas).

Etimologia. O nome foi dado em homenagem a Oscar Valbuena, professor do Departamento de Biologia da Universidad de Carabobo.

Comentários. Esta espécie assemelha-se à $L$. lata (Wiedemann, 1830), diferindo-se desta pelas cerdas verticais externas diferenciadas das cerdas pós-oculares e pelos cercos mais estreitos que os de L. lata em vista posterior.

\section{Lespesia protoginoi (Blanchard, 1966)}

Achaetoneuropsis protoginoi Blanchard, 1966: 28 (Localidade-tipo: Buenos Aires, Argentina).

Lespesia protoginoi; Guimarães, 1971 (combinação de nome para Lespesia), 1983 (revisão das espécies brasileiras).

Diagnose. Parafrontálias e parafaciálias com polinosidade amarelo-pálido.Tergitos 3 a 5 com polinosidade cinza ocupando de forma irregular os três quartos basais; Abdome negro, tergitos 3 a 5 com polinosidade cinza ocupando de forma irregular os três quartos basais. Sintergito $1+2$ sem e tergito 3 com um par de cerdas marginais medianas.

Redescrição. Fêmea. Comprimento: 6,0 - 8,0 mm. Olhos levemente pubescentes. Largura do vértice cerca de 0,30 da largura da cabeça. Parafrontálias e parafaciálias com polinosidade amarelo-pálido. Antenas negras, escapos e pedicelos castanho-alaranjados; flagelômeros cerca de três vezes o tamanho dos pedicelos. Cerdas ocelares ultrapassando a metade do tamanho da distância entre as inserções das cerdas ocelares e a base da antena. Cerdas verticais externas entre um terço e a metade do tamanho das cerdas verticais internas. Dois pares de cerdas orbitais proclinadas. Parafrontálias pilosas externamente às cerdas frontais, com uma fileira de cerdas fracas paralelas às cerdas frontais. Faciálias com cerdas com cerca de um terço a um quarto do tamanho das vibrissas, estendendo-se pouco mais da metade da distância entre as vibrissas e a base das antenas. Escutelo com quatro pares de cerdas laterais, um par de cerdas discais e um par de apicais, obliquas, cruzadas e cerca de menos da metade do tamanho das cerdas subapicais. Tíbias médias com uma cerda ântero-dorsal forte, situada no centro, com o sem uma cerda mais curta situada logo acima. Tíbias posteriores com uma cerda menor que o dobro do tamanho das da fileira de cerdas ântero-dorsais. Garras tarsais mais curtas que o último segmento tarsal. Abdome negro, tergitos 3 a 5 com polinosidade cinza ocupando de forma irregular os três quartos basais. Sintergito $1+2$ sem e tergito 3 com um par de cerdas marginais medianas.

Material examinado. VENEZUELA. Central Matilde de Chivacoa, Yaracuy, 2 fêmeas, X.1971, J.M. Osorio col. (Em Xanthopastis timais).

Distribuição. VENEZUELA(Yaracuy) reg. nov., BRASIL (Sao Paulo, Paraná, Rio Grande do Sul), ARGENTINA (Buenos Aires).

Comentários. Segundo Guimarães (1983), esta espécie se caracteriza pela presença de garras tarsais curtas nos machos. Um novo registro de hospedeiro é dado para a espécie, Xanthopastis timais (Cramer, 1780) (Lepidoptera, Noctuidae).

Lespesia spitzi Guimarães, 1983.

(Figs. 4, 8)

Lespesia spitzi Guimarães, 1983: 21. (Localidade-tipo: Rio de Janeiro, Brasil). 
Diagnose. Parafrontálias e parafaciálias com pilinosidade cinza. Cerdas ocelares curtas, com cerca de um terço do tamanho da distância da fronte entre as cerdas ocelares e a base das antenas. Abdome negro com sintergito 1+2 ao tergito 5 com polinosidade cinza, ocupando de forma irregular os dois terços basais. Sintergito $1+2$ e tergito 3 sem cerdas marginais medianas.

Redescrição. Macho. Comprimento: 7,0 - 10,5 mm. Olhos glabros. Largura do vértice cerca de 0,25 da largura da cabeça. Parafrontálias e parafaciálias com pilinosidade cinza. Antenas negras; flagelômeros cerca de três vezes o tamanho dos pedicelos. Cerdas ocelares curtas, cerca de um terço do tamanho da distância entre as inserções das cerdas ocelares e a base das antenas. Cerdas verticais externas reduzidas. Parafrontálias pilosas externamente as cerdas frontais, com uma fileira de cerdas paralela às frontais, algumas com cerca de mais da metade do tamanho destas. Faciálias com cerdas de aproximadamente um quarto do tamanho das vibrissas, estendendo-se cerca da metade da distância das vibrissas à base das antenas. Escutelo com quatro pares de cerdas laterais, um par de cerdas discais, um par de cerdas apicais, cruzadas e fracas, menos de um terço das cerdas subapicais. Tíbias médias com uma cerda forte ântero-dorsal no meio, acompanhada mais acima de uma cerda com menos da metade do seu tamanho. Tíbias posteriores sem cerdas entre a fileira de cerdas ântero-dorsais. Abdome negro com sintergito $1+2$ ao tergito 5 com polinosidade cinza, ocupando de forma irregular os dois terços basais. Sintergito $1+2$ e tergito 3 sem cerdas marginais medianas. Genitália (Figs. 4 e 8): cercos terminando um pouco além do ápice dos surstilos; em vista lateral, cercos delgados e surstilos afinando-se médioapicalmente, com o ápice digitiforme; em vista posterior, cercos delgados medianamente e levemente arredondados nos ápices.

Material examinado. VENEZUELA. Aragua: El Limón, 2 machos, 24.II.1981/29.I.1981, F.Y. Fernández col.

Distribuição. VENEZUELA (Aragua) reg. nov. , BRASIL (São Paulo).

Comentários. Segundo Guimarães (1983), esta espécie assemelha-se a L. affinis, diferindo-se desta pelo tamanho das cerdas ocelares.

\section{Lespesia erythrocauda (Curran, 1934)}

Frontina erythrocauda Curran, 1934: 516 (Localidade-tipo: Guanoco, Venezuela)

Lespesia erythrocauda; Guimarães, 1971 (catálogo neotropical - a combinação do nome para Lespesia aparece pela primeira vez neste catálogo, mas sem a formalizaçao habitual).

Comentários. Esta espécie foi descrita por Curran (1934) originalmente para o gênero Frontina Meigen, com base em uma fêmea coletada em Guanoco, Estado de Sucre, Venezuela. No catálogo de Guimarães (1971), está posicionada em Lespesia. No entanto, baseando-se em características da descrição original, esta espécie apresenta várias características incompatíveis com as deste gênero, como presença de cerdas discais sobre o tergitos 3 e 4, flagelômero muito estreito e tíbias posteriores com cerdas esparsas. Estas carcterísticas são um forte indício de que esta espécie possivelmente não pertença à Lespesia e que, em uma revisão mais ampla futura, deva ser transferida para outro gênero.

Agradecimentos. Agradeço ao Dr. José Clavijo (MIZA) pelo empréstimo do material estudado e a Dr. Carlos Lamas do Museu de Zoologia da USP pelo envio de referência bibliográfica. Este trabalho se realizou no Departamento de Biologia da "Facultad Experimental de Ciencias y Tecnologia".

\section{REFERÊNCIAS}

Allen, H. W. 1926. Notes on some North American species of Achaetoneura with a description of one new species (Diptera; Tachinidae). Transactions of The American Entomological Society LII: 187-198.

Beneway, D. F. 1963. A revision of the flies of the genus Lespesia (= Achaetoneura) in North America (Diptera: Tachinidae). University of Kansas Science Bulletin 44: 627-686.

Blanchard, E. E. 1959. Dípteros parásitos de orugas de Arctiidae ("gatas peludas”). Revista de Investigaciones Agrícolas 13: 157-182.

Blanchard, E. E. 1966. Descripción de un díptero de la oruga o perro del naranjo Papilio thoas thoantiades Burm. (Lepidoptera). Revista de Investigaciones Agropecuarias 3: 27-31.

Brauer, F. \& J. E. Von Bergenestamm. 1891. Die Zweiflüger des Kaiserlichen Museums zu Wien. V. Vorarbeiten zu einer Monographie der Muscaria Schizometopa (exclusivo Anthomyidae). Pars II. Denkschriften der Kaiserlichen Akademie der Wissenschaften. (MathmatischNaturwissenschaftiche Klasse) 58: 305-446.

Brauer, F. \& J. E. Von Bergenestamm. 1893. Die Zweiflügler des Keiserlichen Museums zu Wien. VI. Vorarbeiten zu einer Monographie der Muscaria Schizometora (exclusive Anthomyidae). Pars III. Denkschriften der Kaiserlichen Akademie der Wissenschaften. (MathmatischNaturwissenschaftiche Klasse) 60: 89-240.

Brèthes, J. 1917. Sur quelques Diptères de Lima (Perou). Anales de Zoologia Aplicada 1: 16-18.

Curran, C. H. 1934. The Diptera of Kartabo, Bartica Distric, British Guiana with descriptions of new species from other British Guiana localities. Bulletin of American Museum of Natural History 66: 287-532.

Guimarães, J. H. 1971. 104. Family Tachinidae. In: N. Papavero (ed.). A catalog of the Diptera of the Americas South of the United States. Museu de Zoologia, Universidade de São Paulo, 333 p.

Guimarães, J. H. 1983. Taxonomy of Brazilian flies of the genus Lespesia Robinaeu-Desvoidy (Diptera, Tachinidae). Papéis Avulsos de Zoologia 35: $11-30$.

ICZN - International Comission on Zoological Nomenclature. 1983. Opinion 1255. Lespesia Robinaeu-Desvoidy, 1863 (Diptera: Tachinidae): designation of type species. Bulletin of Zoological Nomenclature 40: 97-101.

McAlpine, J. F. 1981. Morphology and terminology, p. 9-63. In: McAlpine, J. F. et al (eds.). Manual of Nearctic Diptera. vol. 1, Ottawa, Agriculture Canada, Research Branch Monograph 27, 1674 p.

Notz, A. 1972. Parasitismo de Diptera e Hymenoptera sobre larvas de Spodoptera frugiperda (Smith) (Lepidoptera: Noctuidae) recolectadas en maíz. Maracay, Venezuela. Revista de la Facultad de Agronomía, Universidad Central de Venezuela 6: 5-16.

O'Hara, J.E. \& D.M. Wood. 2004. Catalogue of the Tachinidae (Diptera) of America north of Mexico. Memoirs on Entomology, International 18: $410 \mathrm{p}$.

Riley, C. V. 1871. Third annual report on the noxious, beneficial and other insects, of the State of Missouri. Jefferson City, Public Printer, $195 \mathrm{p}$.

Robineau-Desvoidy, J. B. 1863. Histoire Naturelle des Diptères des Environs de Paris. vol. 2. Paris, Masson et Fils., 1143 p.

Sabrosky, C. W. \& P. H. Jr Arnaud. 1965. Tachinidae. In: A., Stone et al. (eds). A catalog of the Diptera of America north of Mexico. Washington, United States Department of Agriculture Handbook 276. 1696 p.

Sabrosky, C. W. 1979. Lespesia Robineau-Desvoidy, 1863. Proposed 
designation of a type-species under the plenary power (Diptera, Tachinidae). Bulletin of Zoological Nomenclature 35: 243-247.

Sabrosky, C. W. 1980. A revised key to the Nearctic species of Lespesia (Diptera, Tachinidae). Annals of the Entomological Society of America 73: 63-73.

Thompson, W. R.1966. The Tachinds of Trinidad. VII. The larviparous Goniines with broad cheecks (Diptera, Tachinidae). Studia Entomologica 8 (1965): 353-443.

Townsend, C. H. T. 1908. The taxonomy of the muscoidean flies, including descriptions of new genera and species. Smithsonian Miscellaneous Collections 51: 1-138.

Townsend, C. H. T. 1909. Descriptions of some new Tachinidae. Annals of the Entomological Society of America 2: 243-250.

Townsend, C. H. T. 1915. New Neotropical muscoid flies. Proceedings of the United States National Museum 49: 405-440.
Townsend, C. H. T. 1916a. New Muscoid genera (Dipt.). Entomological News 27: 178.

Townsend, C. H. T. 1916b. Some new North American muscoid forms. Insecutor Inscitiae Menstruus 4: 73-78.

Townsend, C. H. T. 1927. Synopse dos gêneros muscoideos da região humida tropical da América, com gêneros e espécies novas. Revista do Museu Paulista 15: 203-385.

Townsend, C. H. T. 1941. Manual of Myiology. Part XI. Itaquaquecetuba, Charles Townsend \& Filhos, 242 p.

Webber, R. T. 1930. A revision of the North American tachinid flies of the genus Achaetoneura. Proceedings of the United States National Museum 78: 1-37.

Williston, S. W. 1889. The dipterous parasites of North American butterflies, p. 1912-1924. In: S. H. Scudder. Butterflies of the Eastern United States and Canada, vol 3, Cambridge, 1775-1958.

Recebido em 16/02/2009; aceito em 15/04/2010

Editor: Sílvio Shigueo Nihei 